\title{
El arte de boticario durante la primera mitad del siglo XVII en el Nuevo Reino de Granada
}

\author{
Paula Ronderos \\ Pontificia Universidad Javeriana, Colombia \\ paularonderos@yahoo.es
}

\begin{abstract}
Resumen
Este artículo caracteriza los escenarios de la farmacia de la primera mitad del siglo XVII a partir del análisis de las boticas y del entorno de los boticarios que dejaron huellas en documentos judiciales como las visitas, los exámenes de titulación y las recetas. Se reconstruyen algunas dinámicas de producción, circulación y uso de sustancias medicinales en el Nuevo Reino de Granada.
\end{abstract}

Palabras clave: farmacia, boticarios, historia colonial, siglo XVII, Nuevo Reino de Granada, saberes y prácticas.

\begin{abstract}
This article characterizes pharmaceutical spaces of the first half of the $17^{\text {th }}$ century. The analysis of knowledge and practice, places and techniques that made the system work, allows us to describe and explain the dynamics of production, circulation and use of medical substances in the Nuevo Reino de Granada.
\end{abstract}

Key words: Pharmacy, boticarios, colonial history, Nuevo Reino de Granada, knowledge and practice.

\section{Introducción}

Durante el siglo XVII la labor de boticario exigía un ambiente propicio, una serie de instrumentos, sustancias indicadas y adecuadas y un lugar donde realizar las mezclas, conservar las medicinas y comercializarlas. Según la investigación de Martha Rodríguez sobre boticas en Nueva España, para poder fundar una botica:

El local debía tener tres habitaciones, la primera donde estaban los anaqueles y se atendía al público; la rebotica, donde se almacenaban las yerbas y demás 


\section{FRONTERAS}

de la fistoria

Vol.12 / 2007

productos, y por último, el obrador, donde se elaboraban los medicamentos. (158-59)

Siguiendo a Rodríguez, este artículo se divide en tres apartados que buscan reconstruir las boticas neogranadinas en su contexto y explicar las tres dimensiones que caracterizaban a la botica dentro del contexto urbano colonial. En primer lugar, con base en documentos de visitas a boticas, se establecerán las redes comerciales para analizar los problemas de jurisdicción, abastecimiento y competencia que condicionaban la venta de remedios. En un segundo apartado se hará alusión a las habilidades y conocimientos necesarios en la fabricación de medicinas. Finalmente, se identificarán los usos de las medicinas a partir de las recetas que circulaban entre médicos, cirujanos y boticarios.

\section{Redes comerciales: circulación de remedios}

Para participar en el gremio médico, lo primero que debía hacer un boticario era fundar una botica. Tanto los boticarios como las boticas eran objeto de control de visitadores, quienes revisaban los títulos, el suficiente abastecimiento y las condiciones de conservación de las sustancias (Lanning) ${ }^{1}$. Al igual que otros mecanismos de control administrativo colonial, las visitas seguían una estructura predeterminada que no se manifiesta explícitamente dentro de los pleitos que se encuentran por su causa; sin embargo, es claro que se revisaba la cantidad y la calidad de los remedios, la existencia de artefactos para su preparación y los títulos y cualificaciones del boticario (Pastor).

En un documento fechado en 1634 en Cartagena de Indias, se registró un pleito ante la Audiencia en el cual tres boticarios, Sánchez, Cueto y Mogueines, acusaron al visitador de boticas, el cirujano Martín Sánchez, de no haber cumplido con los procedimientos estipulados en las leyes y haber cobrado sumas por la visita que no se acostumbraban (AGN, MA 6, ff. 880-1033). Según los boticarios, el cirujano Sánchez estaba ejerciendo simultáneamente como cirujano, boticario y visitador, lo cual iba en contra de las reglas y costumbres del gremio, pues el hecho de que ejerciera simultáneamente como boticario y cirujano hacía que no tuviera el tiempo necesario para dedicarse a la fabricación de medicinas y terminara por delegar esas funciones en su hijo, quien no sabía

\footnotetext{
${ }^{1}$ Las visitas en el periodo colonial eran actos de jurisdicción con los que se pasaba revista del estado de las cosas, tanto de gentes como de mercancías. Vénase las múltiples acepciones de este término en el Diccionario de Autoridades.
} 
el arte. Para defenderse de esta acusación, Martín Sánchez aseguró que su hijo tenía mucha experiencia aún cuando no estaba titulado y argumentó que no era cierto que no tuviera tiempo, pues a su labor de cirujano sólo dedicaba dos horas en la mañana, y el resto lo empleaba en la atención de su botica ${ }^{2}$.

En su defensa, el cirujano Sánchez acusó a los tres boticarios de no atender sus boticas directamente y de encomendar a otros el delicado trabajo. Ninguno de los tres se salvó, pues, según el visitador, Francisco Sánchez tenía en el despacho de su botica a un negro que no sabía leer ni escribir, por lo que buscaba personas que le leyeran lo que se venía a buscar; la botica de Mogueines estaba atendida por un indio, y la de Juan Cueto, por un grumete de barco.

Estas acusaciones, teniendo presente que hacen parte de un pleito en el que se busca desprestigiar al contendor, dan pistas interesantes acerca de las dinámicas culturales que coexistían en los establecimientos. La presencia de un negro, un indio y un grumete de barco ilustran acerca de los posibles intercambios culturales, necesarios para el aumento de los conocimientos en el arte. Es difícil precisar la cantidad y calidad de estos intercambios y es posible que los ayudantes de botica cumplieran con una función comercial y no ayudaran directamente en la recolección de simples ni en la fabricación de sustancias. Sin embargo, también es probable que ayudaran al boticario en las artes manuales de su oficio y en ocasiones tuvieran la oportunidad de incluir en las mezclas sus conocimientos específicos adquiridos en ámbitos distintos a la tradición letrada española.

Los tres boticarios enfatizaron que no sólo era perjudicial que el dueño de una botica hiciese las visitas, sino que, por ser cirujano, estaba incumpliendo la ley. El argumento era que el médico o el cirujano que también era dueño de botica gastaba primero las peores medicinas para sacar provecho de las buenas, y con este criterio aplicaba cuatro medicamentos generales para todas las enfermedades (AGN, MA 6, ff. 880-1033).

\footnotetext{
${ }^{2}$ La presencia del hijo de Martín Sánchez muestra la dinámica del aprendiz. Seguramente los cuatro años de experiencia solicitados por los examinadores se referían precisamente a haber sido mozo de botica y haber atendido una botica ajena, requisito fundamental para convertirse en especialista, claro, junto con el manejo adecuado de los manuales de identificación y las dinámicas de la fabricación de fórmulas.
} 


\section{FRONTERAS}

de la fistoria

En la legislación se estipulaba que no era lo mismo ser médico que cirujano, ni barbero que boticario ${ }^{3}$. Sin embargo, las fronteras entre los oficios no se encontraban delimitadas de forma contundente, y la práctica simultánea fue muy común en el Nuevo Reino de Granada durante la primera mitad del XVII, según lo atestigua la documentación consultada. A este respecto se encontraron dos casos, uno en Pamplona (Norte de Santander, 1613) y el otro en Tunja (Boyacá, 1618).

En el primero, el cirujano Pedro Gómez de Andrada, quien ejercía en Pamplona, después de ordenar en su testamento el destino de su cuerpo y las disposiciones para su alma, menciona que posee en Pamplona una botica que compró y dotó aún cuando no la había terminado de pagar todavía. En este caso no se presentó ninguna querella que aludiera al delito del doble oficio (AHP, $A N 16$, ff. 64-67). En Tunja, aunque no se encontraron referencias claras a boticas que estuvieran funcionando durante el siglo XVII, sí se menciona el problema de la cura de enfermedades con utilización de medicinas por parte de médicos y cirujanos graduados y no graduados, pero no se presentaron problemas por doble ejercicio (AGN, $M A$ 1, ff. 621-628).

En el pleito de 1634, después de la demanda al cirujano por considerar que no tenía la jurisdicción para visitar boticas, los tres boticarios de Cartagena se centraron en el problema del abastecimiento. El visitador había multado a los boticarios por falta de abastecimiento, y ellos consideraban que no era justo, ya que la botica del cirujano estaba desprovista de las sustancias más básicas. Para los boticarios, el abastecimiento suficiente debía incluir una serie de medicinas de primera necesidad que estuvieran en aceptables condiciones de conservación y un buen número de medicinas complejas que asegurara que los boticarios cumplieran con su función de proveedores dentro del sistema médico.

Los tres boticarios acusaron al cirujano Sánchez de haber comprado una botica en sólo 1.000 pesos de plata, precio bajo que se justificaba porque estaba desproveída; testificaron que, además, nunca lo habían visto surtirse de los

\footnotetext{
${ }^{3}$ Según la legislación y de acuerdo con las evidencias de la práctica, en el período colonial no era lo mismo ser boticario que médico, ni médico que cirujano. Si pudiéramos establecer una jerarquía, primero vendría el médico, quien se encargaba de las enfermedades internas. Luego, el cirujano, que curaba las externas. Finalmente, el barbero, quien se encargaba de afeitar, sangrar y sacar muelas. Hay que considerar que, formalmente, el cirujano y el barbero pertenecían a un mismo grupo y se diferenciaban de los médicos porque no sabían latín. Los boticarios pueden considerarse como pertenecientes a otro gremio que quizás no tenía tanta alcurnia, pero sí importancia, por cuanto los médicos tenían prohibido realizar por sí mismos los medicamentos.
} 
galeones, sino que compraba sobras a barberos (AGN, $M A$ 6, ff. 880-1033). Tampoco entendían cómo era posible que el cirujano nunca hubiera pedido prestados simples a otros boticarios. Este hecho era interpretado como prueba de la mala botica que tenía, pues, según los boticarios acusadores, el préstamo no sólo era costumbre, sino una permanente necesidad aun en las boticas mejor abastecidas.

Sin embargo una cosa era estar en Cartagena de Indias, donde llegaban los galeones y se surtían las boticas, y otra muy distinta, en una ciudad como Santafé, tan lejos del mar y tan arriba en la montaña. Como el abastecimiento era fundamental para el buen funcionamiento, los boticarios podían asociarse para comprar y llevar medicamentos ${ }^{4}$. Así, los boticarios no se dedicaron única y exclusivamente a fabricar y vender sustancias con fines terapéuticos. Para la primera mitad del XVII ellos aparecen como sujetos a quienes se les daba poder y agencia para la administración de negocios (AHP, $A N$ 20, f. 31). Así mismo, los cirujanos y los médicos se establecían como socios de compañías comerciales de importaciones provenientes de España. Esto es bastante comprensible si se tiene en cuenta el valor agregado que tenían los bienes útiles en la vida cotidiana: sombreros y telas, mesas, vinos y medicamentos.

La botica era un negocio que podía ser muy rentable ${ }^{5}$. Había que tener amigos médicos y cirujanos que recomendaran el local, no tener problemas con la autoridad, tenerlo bien surtido y preparar medicinas de buena calidad. Pero esa buena fortuna podía verse amenazada cuando bajaba la capacidad adquisitiva, por ejemplo cuando los pueblos decaían económicamente o cuando aparecía un nuevo boticario con sus trastes dispuesto a poner competencia.

En 1600, en la ciudad de Zaragoza (Antioquia), se presentó un pleito por asuntos de monopolio y competencia entre los boticarios Diego Ordóñez y Duarte López de Vega (AGN, MA 1, ff. 90-137). López de Vega era un portugués que llegó a Zaragoza con la idea de fundar una botica. Ordóñez, quien poseía una botica en la ciudad, arremetió en su contra para demostrar que

\footnotetext{
${ }^{4}$ En uno de los testamentos del boticario Diego Ordóñez de Taboada, por ejemplo, se menciona su sociedad con Pedro Gutiérrez de Carvajal, también boticario, para transportar sustancias desde Cartagena de Indias. Ordóñez había invertido en el negocio 100 reales de a 8 y pidió prestados a Gutiérrez 100 pesos de oro de 22 quilates para adquirir medicinas para su botica, las cuales debían ser llevadas desde Cartagena. Una vez llegaran a Santafé y fueran vendidas, Gutiérrez recuperaría su dinero.

${ }^{5}$ La tasación de la botica de Diego Ordóñez en Santafé, incluyendo el valor de las sustancias y los artefactos en ella contenidos, ascendió a 3.393,5 pesos (AGN, TC 20).
} 


\section{FRONTERAS}

de la historia

su botica era suficiente para el poblado y que López de Vega no tenía las cualificaciones necesarias para administrar una propia. El extenso expediente reúne diferentes cuestionarios aplicados a testigos de una y otra parte.

López de Vega, por su parte, anexó el testimonio de un médico que justificaba la necesidad de una segunda botica en Zaragoza para la atención de las múltiples enfermedades que aquejaban a la población. El caso fue remitido a la Audiencia de Santafé, pero no se sabe si López de Vega pudo fundar su botica ni si los argumentos del médico fueron contundentes. La última anotación del portugués es una carta donde manifiesta su total devoción por la Corona española y afirma que se acoge a todas sus disposiciones y deseos.

Las rencillas entre sectores del gremio de la medicina eran comunes y son la causa fundamental de su aparición dentro de los archivos judiciales del periodo colonial. La competencia en el mercado hacía que llevaran a instancias judiciales sus pleitos, y los implicados se enfrascaban en largos y costosos juicios que a la larga no resolvían la situación. Cirujanos, médicos y boticarios deseaban que su oficio fuera restrictivo a quienes habían estudiado la especialización y poseían las capacidades económicas y materiales para su ejercicio, y por tanto era molesto para unos y otros cuando un especialista en otra área husmeaba y se lucraba en los terrenos de ésta.

Las fuentes que mencionan los demás sistemas terapéuticos relacionados con medicamentos, normalmente los vinculan con delitos o situaciones anormales que escapaban de la legislación y los controles del sistema médico. Para visualizar el panorama de relaciones entre diversos sistemas, así como las características de aquellos que podríamos llamar alternativos, es necesario acudir a cierto tipo de documentación sobre el uso de plantas y otras sustancias medicamentosas por parte de otros grupos sociales. Un ejemplo de esta competencia no restrictiva al sistema médico ordenado y controlado por la administración colonial puede extraerse de las narraciones extraordinarias de Méndez Nieto. En una de sus curas en Santo Domingo, un paciente grave

[...] tuvo por mejor consejo curarse con Villasanta, famosa curandera y aún hechicera de aquel tiempo, la cual le prometió sacarle toda el agua y deshincharlo en menos de veinte horas, y esto sin darle purga ni abrirlo. Y lo hizo y cumplió como lo dijo; y fue de esta manera. Cogió unas hojas de higuereta de infierno que ella bien tenía conocidas y experimentadas por ser planta de su tierra y patria, majolas juntamente con cantidad de cantáridas frescas, de que el matadero de aquella ciudad tiene abundancia; y así majadas, se las aplicó a las espinillas de entre ambas piernas, atadas con sendas vendas; $y$, dejándolo así por 
aquella noche, cuando vino a la mañana, tenía hechas dos grandes llagas y fuentes, en cada pierna suya, que, goteando aprisa y destilando una agua amarilla salada, que no difería cosa de una cruda y delgada orina. (186)

Según el doctor Méndez, el paciente no volvió a despertarse y la hechicera dejó la ciudad. Acudir a una u otra terapia era decisión del paciente y dependía de sus medios económicos y creencias. Aunque es probable que se utilizaran todas las estrategias posibles ante una enfermedad postrante y existían múltiples alternativas terapéuticas provenientes de tradiciones distintas, la medicina renacentista que utilizaba como proveedor al boticario tenía espacios de acción determinados. Existía una gama determinada de patologías que correspondían con un sistema terapéutico donde existían unos humores que podían ser evacuados, secarse o madurarse a partir de la administración de sustancias cuyas virtudes específicas se vinculaban directamente con la dolencia.

Los controles por parte de la administración colonial permitían vigilar que las artes de botica fueran ejercidas, en el ámbito urbano, por funcionarios calificados según parámetros establecidos desde la legislación y que eran aplicados tanto en España como en las colonias. A partir de la documentación, es posible determinar que dichos controles no fueron tan rigurosos como se suponía que debían serlo y que fue común que se tergiversaran e incumplieran las normas. Sin embargo, los conocimientos que debían poseer los boticarios fueron evaluados y controlados por medio de la solicitud de títulos de aval para el ejercicio.

Es difícil medir qué tan efectivas eran las visitas, pues seguramente al saber de la inminente llegada de los visitadores, los boticarios debían poner en acción múltiples estrategias de camuflaje, ocultamiento y préstamo. Las dos primeras estrategias correspondían al ámbito individual de la práctica, mientras que la última remitía a ciertas alianzas entre colegas.

\section{Producción de remedios en el Nuevo Reino de Granada durante el siglo XVII}

Cuando se llevaban ante la audiencia pleitos que involucraban a miembros del gremio médico, sea cual fuere su especialización, éstos debían legitimar su ejercicio por medio de la presentación de los títulos correspondientes que los avalaban. Cada especialización poseía un tipo de título particular en el que se determinaban las prácticas que estaba autorizado a realizar el portador, así como los límites de su ejercicio. En el caso de los cirujanos, por ejemplo, era común 


\section{FRONTERAS}

de la historia

que en los títulos figurara que no tenían autorización para realizar ciertos drenajes de humores en los pacientes sin la autorización previa de un médico (AGN, $M$ 11).

Los títulos de boticario podían adquirirse por medio de la presentación de un examen ante autoridades, protomédicos o médicos reconocidos. Haber adquirido el título en España o en Santafé, en términos prácticos, tenía la misma legitimidad; por tanto, se encuentran documentos donde se mencionan exámenes presentados ante médicos españoles en Sevilla, ante protomédicos como Álvaro Auñón de Cañizares o Mendo López del Campo en Santafé y hasta en otros lugares de América, como el Perú (AHP, $A N$ 27, ff. 222-25; AGN, $M$ 11, ff. 785-864).

El candidato debía demostrar que tenía cuatro años de experiencia en botica de boticario titulado y que era mayor de 25 años. Luego, seguía el examen en sí. En primer lugar se le evaluaba la latinidad y la teoría, y en una segunda parte, llevándolo a una botica, se examinaban las prácticas, el conocimiento de las drogas y simples, la elección de yerbas, la conservación, preparación y duración de las sustancias y, finalmente, los modos de conseguir las compuestas (AGN, MA 6, ff. 880-1033).

En este examen se condensaban los elementos fundamentales de la teoría farmacéutica del siglo XVII. De tradición islámica, el arte de botica se basaba en la comprensión de las cualidades de los medicamentos simples, las formas y tipos de composición y las características de almacenamiento, conservación y longevidad de las sustancias (Martínez de Leache, Discurso; Rodríguez de Tudela). Las tres áreas evaluadas implicaban el conocimiento empírico, en ocasiones teórico, de los cánones farmacéuticos.

En este punto cabe plantear la inquietud acerca de las formas como se llevaban a cabo los exámenes practicados en el Nuevo Mundo y sus diferencias con los europeos. No solamente en cuanto a la identificación de las yerbas, que en el Nuevo Reino podían ser distintas o estar secas, sino también en cuanto a los criterios de conservación, que tendrían valores diferentes de acuerdo con las características climáticas particulares de las tierras americanas. Desafortunadamente, la documentación consultada hasta el momento sólo permite evidenciar, en términos formales, la importancia de los exámenes y los títulos, mas no determinar la especificidad de los contenidos evaluados. 
Durante los siglos XVI y XVII, en España puede hablarse de un renacimiento médico que incluyó dentro de la tradición galénica las obras de autores de origen islámico como Avicena y Mesue. Si bien es costumbre creer que la España de la Conquista, recién salida de la Reconquista, profesaba una aversión por todo aquello que fuese moro o judío, en el ámbito de la medicina, la cirugía y la farmacia se acoplaron las teorías útiles de ambas tradiciones culturales. Mesue, por ejemplo, constituyó el pilar del sistema farmacéutico y su obra fue reeditada, comentada y ampliada durante los siglos XVI y XVII ${ }^{6}$.

Este fenómeno produjo un renacimiento de la producción literaria en el ámbito de la medicina, donde son importantes autores como Andrés Laguna y Nicolás Monardes ${ }^{7}$. Existen numerosos libros de discursos epistemológicos sobre el cuerpo, y es común encontrar textos con instrucciones prácticas para componer una pierna rota, extraer un veneno o fabricar medicinas ${ }^{8}$.

Los boticarios tenían un vínculo particular con los saberes trasmitidos por vía escrita, pues, aunque aprendían el oficio como mozos de botica, tanto la identificación de las plantas, trozos animales o minerales, como la correcta preparación de una fórmula llena de dracmas y hervores, dependían de la adecuada, pertinente y acertada consulta de un libro de texto (Pastor) ${ }^{9}$.

\footnotetext{
${ }^{6}$ Por ejemplo, en 1569 se publicó en Alcalá el trabajo del boticario Aguilera, y en Zaragoza, en 1662 se imprimió el Tratado de Martínez de Leache.

${ }^{7}$ Ambos textos se pueden consultar en la biblioteca digital de la Universidad Complutense de Madrid: $<$ http://cisne.sim.ucm.es/>.

${ }^{8}$ La Universidad de Madison realizó durante 1997 un trabajo de trascripción de manuscritos antiguos sobre medicina, cirugía y farmacia españolas de los siglos XV y XVII (Herrera y Gonzá de Fauve). A partir de su consulta ha sido posible distinguir estos tipos de literatura que circularon durante el periodo colonial. Si bien dicha circulación se refiere a la Península Ibérica, es de suponer que muchos de ellos llegaron con los especialistas, debido a la utilidad que tenían para el ejercicio. Debo al profesor Jaime Borja el acceso a la base digital que desarrolló la Universidad.

${ }^{9}$ Entre los libros antiguos que se conservan en Bogotá existen dos ejemplares que hicieron parte de la botica de la Compañía de Jesús. Uno de ellos reposa en la Biblioteca de la Universidad Javeriana, ejemplar de Materia médica, de Dioscórides (1543), impresionante compendio de animales, plantas y minerales utilizados por la tradición romana que fue paradigma de la botánica útil y la medicina hasta entrado el siglo XVIII. El segundo se titula Discursos pharmaceuticos sobre los cánones de Mesue, de Miguel Martínez de Leache (1652), cuyo primer ejemplar se encuentra en la Biblioteca Nacional. Es de suponer que ambos textos eran de consulta permanente, pues allí se encontraba la información para recoger una sustancia, extraer de ella las virtudes deseadas y mezclarla con otras para producir sustancias mixtas, complejas y procesadas. Las fórmulas contenidas en estos textos adquirían mucho valor en un universo extenso de
} 


\section{FRONTERAS}

de la fistoria

En el siglo XVII, los boticarios instalados en una población donde residían vecinos españoles podían fabricar diferentes tipos de medicinas, las cuales pueden catalogarse, según los grados de complejidad, en términos de las dinámicas ejercidas sobre ellas en cuanto procesos de transformación. Estas categorías, comunes entre los siglos XVI y XVIII tanto en la península ibérica como en las colonias americanas, incluyen tres tipos de medicamentos: las sustancias simples, es decir, elementos naturales con escasa o ninguna transformación técnica administrados para la cura de enfermedades generales; las sustancias preparadas, que se refieren a sustancias simples que habían pasado por algún proceso leve de transformación, como los polvos, las rasuras y la elixación; finalmente, las sustancias compuestas, mezclas de dos o más simples que eran posibles gracias a la utilización de diferentes mecanismos técnicos como la destilación y el cocimiento (Pastor).

Para conocer las propiedades de las diferentes sustancias, fuera en su presentación simple o como partes de una mezcla, los boticarios se servían de manuales europeos y de su experiencia particular en el campo. Es probable que el carácter empírico estuviera ligado directamente con la recolección de sustancias y los procesos de transformación, mientras que el uso específico de artefactos para realizar las mezclas se encontraba vinculado con las tradiciones europeas. En este sentido, resultaba necesario el reconocimiento del entorno natural y cultural donde se desarrollaban las prácticas, un contexto contingente que determinaba las características del oficio en el Nuevo Reino de Granada.

Las sustancias utilizadas en las boticas podían obtenerse de diferentes maneras. Como las plantas medicinales eran las sustancias más utilizadas en las medicinas, el boticario podía plantar ciertas simientes en su solar y cultivarlas. Esta modalidad sólo funcionaba cuando las plantas habían sido aclimatadas o si se trataba de plantas autóctonas americanas. Si el boticario no tenía su propio cultivo, podía comprar las sustancias, plantas u otros simples sin dificultad en los mercados y tiendas ${ }^{10}$. Si las sustancias eran de difícil consecución, por ejemplo un producto vegetal, como los mirabolanos cetrinos, o medicinas ya preparadas, como los colirios para males oculares, los boticarios podían pagar a

sustancias que se inscribían en un vasto juego de combinatoria donde cada una poseía una variada gama de usos y podía ser combinada con otras por medio de diversas estrategias de composición.

${ }^{10}$ En el inventario de la tienda de Diego de Ybarra (1644), entre camándulas, cuchillos, botones, hilos y listones, se encuentran algunos simples utilizados comúnmente en las boticas. Entre ellos, solimán (mercurio utilizado para blanquear la piel), romero, cebadilla, cardenillo, piedra alumbre y cañafístula (AGN, $N$ 1, ff. 232-238). 
importadores o asociarse en compañías mercantiles y hacer ellos mismos las transacciones ante las autoridades portuarias.

La identificación de la planta era una labor muy difícil, pues no existía un lenguaje botánico común que permitiera realizar un intercambio en términos nominales. Las plantas seguramente eran nuevas tanto para africanos como para españoles. Podía darse que sólo uno de ellos hubiera incorporado la especie en su sistema o que cada uno tuviera una explicación y uso atribuido a la planta. Sin un nombre común, debía hacerse la identificación de caracteres como el color y las formas (Font Quer).

Si bien existió un mercado de importación de algunos componentes, así como el cultivo mediante la aclimatación de especies, también se daba el reemplazo de sustancias por otras que fueran más sencillas de conseguir. Aunque los boticarios seguían las recetas que se encontraban en sus manuales y farmacopeas, ciertas sustancias no podían conseguirse. En estos casos se ponía en marcha la figura del sine pro quo. Esta noción se refería a la posibilidad de reemplazar una sustancia por otra que poseyera las mismas cualidades y permitiera el balance de la mezcla (Siraisi 143). En el caso de los boticarios en Indias, esta figura debió haber sido bastante común debido a los nuevos conocimientos acerca de sustancias medicamentosas naturales particulares del Nuevo Mundo, y gracias al contacto con otras culturas y a la experimentación directa.

La transformación de los saberes no se restringía a la identificación de las sustancias, sino que estaba determinada por la correcta utilización de éstas, pues, aunque se tuviera en las manos la planta adecuada, no servía de nada si no se sabía cómo utilizarla y para qué.

Para poder realizar las pócimas, polvos y demás preparaciones, era necesario disponer de un conjunto de instrumentos y artefactos. De nada servían los manuales y la pericia del boticario si no tenía un alambique o un almirez ${ }^{11}$. La dotación de la botica probablemente era traída en baúles desde España aunque no se debe descartar fabricación o reparación en las ciudades con ayuda de herreros o vidrieros.

\footnotetext{
${ }^{11}$ En el expediente que se refiere a la muerte del boticario Diego Ordóñez de Taboada se incluye un extenso y completo inventario de la botica que este manejaba en la ciudad de Santa fé. Entre los implementos de la botica se encontraban varios alambiques, morteros, cazoletas, espátulas y un dramario. Estos elementos resultaban imprescindibles para el trabajo en la botica y constituían valores materiales y simbólicos imprescindibles para la profesión (AGN, TC 20).
} 


\section{FRONTERAS}

de la historia

Teniendo a la mano un arsenal de simples de diversas procedencias, el boticario debía proceder a su transformación. Ésta era posible por la articulación de una estructura de saberes acerca de las incidencias de los fenómenos físicos en el cuerpo con la utilización de técnicas para la composición de diversos tipos de sustancias complejas. La estructura de dicho sistema procedía de la combinación de categorías heredadas del mundo clásico europeo, de autores griegos y romanos y de la tradición árabe (Laín).

Una vez el remedio estaba fabricado según las normas y técnicas necesarias para pasar una inspección, el boticario debía comercializarlo. Esta dinámica era posible gracias a que la demanda sobre el producto estaba asegurada por el funcionamiento mismo del gremio médico. Las medicinas de botica y su circulación estaban garantizadas dentro de un mercado urbano donde eran consideradas como terapias efectivas para combatir las enfermedades de los individuos. Se hace mención explícita a la idea de lo urbano en el contexto colonial, pues el protomedicato tenía su jurisdicción restringida a los pueblos de españoles y durante el siglo XVII no se inmiscuía en el ámbito rural, en el que deben incluirse resguardos, plantaciones, haciendas productivas y otros lugares del territorio ${ }^{12}$.

El mercado de sustancias con fines terapéuticos se inscribía en un complejo escenario cultural que se caracterizaba por relaciones interétnicas. Existían muchos mecanismos y estrategias para la utilización de sustancias que dependían de la ubicación del enfermo, de sus creencias y de sus posibilidades económicas. En este sentido, las medicinas de botica cumplían su papel dentro de una compleja red donde las necesidades terapéuticas estaban estrechamente vinculadas con los valores culturales y simbólicos que eran utilizados para comprender el cuerpo enfermo.

Es probable que los españoles residentes en los pueblos acudieran a medicamentos indígenas o de tradición negra por fuera del sistema médico y sin la necesidad de rendir cuentas por ello ante nadie. Este tipo de costumbres escapan de la información que se ha encontrado hasta ahora en los documentos. Sin embargo, sí permite establecer algunas líneas generales que explican las condiciones del mercado de sustancias medicinales.

\footnotetext{
${ }^{12}$ La jurisdicción del protomedicato es estipulada en la Ley Primera de Felipe II (1570). Recopilación f. 159v.
} 


\section{Usos de las medicinas de botica en el Nuevo Reino de Granada}

Los vínculos entre paciente, médico o cirujano y boticario eran posibles dentro de un sistema que funcionaba por medio de las recetas. En teoría, el cirujano o el médico visitaban a un enfermo en su lugar de residencia o el enfermo acudía a la casa del médico. Éste analizaba los síntomas y decidía qué tipo de terapia era la más acertada para combatir la enfermedad.

En un plano ideal, el médico recetaba al enfermo, y el boticario le procuraba las medicinas indicadas para curar la enfermedad. A partir de los documentos parece que la comunicación entre el médico y el boticario se daba por escrito y oralmente; las prescripciones que se hacían por escrito se denominaban cédulas. Sin embargo, también era posible adquirir sustancias medicinales directamente en la botica, pues el boticario recetaba según su experiencia, ahorrando al cliente el pago de dos cuentas, una para el médico y la otra por la medicina.

En los documentos coloniales que relacionan pleitos judiciales de boticarios e inventarios de boticas existen evidencias de cuentas de cobro que especifican las medicinas entregadas a los pacientes durante el tratamiento. A partir de estos documentos - normalmente piezas pequeñas de papel insertadas entre los folios de los expedientes - puede observarse que a la hora de comprar medicamentos una opción era adquirirlos de contado, pero también se fiaba o se entregaban objetos valiosos como prenda. Los remedios se consignaban en las cuentas en forma de listados que eran tasados por un médico escogido por el estamento judicial a cargo.

A partir de dos ejemplos de pleitos donde se encuentran recetas, se presentan dos formas en las que circulaban remedios de botica en el contexto colonial. El primero se refiere a las medicinas recetadas y entregadas directamente por un boticario, en el segundo se hacen explícitos los vínculos entre boticario, cirujano y médico a la hora de recetar.

El primer caso es un documento fechado en 1627 donde se refiere el tratamiento que se le dio a un reo (AGN, $C$ 17). Aunque la lista es mucho más corta que la de Ordóñez, es asombrosamente extensa para tratarse de sustancias ingeridas por un solo individuo, muchas en más de cinco ocasiones. La suma total de las recetas asciende a 107 pesos. Según las medicinas que le fueron suministradas a Manuel Álvarez, el reo tenía un grave problema de ojos, por lo que utilizó colirios en repetidas oportunidades. También le fueron recetados varios remedios con intención digestiva, así como aceites para confortar dolores. En la 


\section{FRONTERAS}

de la historia

cuenta realizada por el boticario López de Buiza no se mencionan cédulas firmadas por un médico o un cirujano en las que se ordenara la administración de los medicamentos, por lo que es posible que fuera el mismo López de Buiza quien recetara por su cuenta y riesgo las sustancias. Esta idea se corrobora con un antecedente, pues en 1626 este personaje se había visto involucrado en un caso criminal donde era acusado de haber suministrado una purga asesina sin la previa autorización médica.

El caso referido se dio a raíz de la muerte del mercader Melchor Rico, quien debido a un agudo problema intestinal acudió a su médico de cabecera, el cual le recetó una purga hecha de sen y maná, sustancias cordiales y de poca peligrosidad. Aparentemente, Melchor, al no sentir ninguna mejoría, envió a uno de sus empleados a la botica de Buiza con dinero suficiente para comprar otra purga. El dictamen posterior a la autopsia llevó al protomédico Mendo López a concluir que efectivamente el exceso de purga había incidido fatídicamente en la suerte del mercader, regando el humor maligno por todo el cuerpo, hinchándolo en extremo y llevándolo a la muerte.

Sin embargo, las recetas también funcionaban como vínculos entre profesionales especializados dentro del sistema médico y sirven para comprender los diferentes tipos de enfermedades y el uso de las sustancias en el contexto. Entre 1598 y 1603, Diego Ordóñez llevó ante la audiencia de Santafé un pleito contra el alguacil de Zaragoza (Antioquia), Diego López del Riego, a causa una deuda de 300 pesos por unos medicamentos que le habían sido entregados para su cura personal y la de sus esclavos de mina (AGN, ACC 20, ff. 732-791). En primera instancia, Ordóñez presentó el caso anexando las correspondientes recetas que testificaban que las medicinas habían sido entregadas. Cuando el caso fue revisado, dos años después, las recetas habían desaparecido. Se culpó al escribano por no haberlas cosido debidamente al expediente, lo que había causado su pérdida. Con los vales de rectas desaparecidos, Ordóñez procedió a elaborar un listado de las medicinas que según él habían sido entregadas a López del Riego.

El listado comprende a muchos sujetos y se extiende por varios años. La primera fecha que aparece es 1594, y la última, 1597. Ordóñez incluye en ella una cantidad de medicamentos utilizados, acompañada de una descripción de la medicina y su valor. También se menciona el sujeto a quien fue suministrada y la cantidad de veces que fue necesario repetirla. La cuenta incluía parientes, empleados y negros esclavos. En términos de la terapéutica, la presencia de negros esclavos como sujetos de las prácticas españolas resulta interesante. En 
el listado, se mencionan reiteradamente curas para negros y negras, básicamente en el tratamiento de problemas digestivos y de accidentes de trabajo, en los que se incluyen problemas de rodillas, piernas y brazos rotos. Estas terapias son solicitadas bajo cédulas firmadas por un cirujano, mientras que las que involucran familiares de López del Riego o a él mismo, iban firmadas por un doctor.

Se presentan bebedizos múltiples a base de plantas, destinados a purgas o a generar reacciones puntuales en humores acumulados o faltantes. Puede observarse una importante presencia de aceites y azúcares, así como ungüentos varios, colirios y emplastos. Durante el siglo XVII muchas medicinas aparecían denominadas según los efectos que generaban en el cuerpo humano y se adicionan adjetivos que explican su función. En el listado, se presentan sustancias digestivas, mundificativas, coléricas y desopilativas.

Ante la cuenta, López del Riego exigió una nueva tasación por considerar que se presentaba un abuso en los precios. También mencionó que a él no se le había entregado esa cantidad de medicinas y que los vales no aparecían firmados por él. Es interesante el hecho de que existiera la posibilidad de abrir cuenta en la botica y acumular una suma de 300 pesos en medicinas durante cuatro años. El sistema de crédito parece haber asegurado al boticario una clientela, pero lo ponía en aprietos a la hora de cobrar.

A partir de las recetas es posible observar la operación de dos tipos de medicina definidas según el profesional que escribía la receta y de acuerdo con el tipo de enfermedad que se trataba. Estos dos tipos de medicina pueden comprenderse a la luz de las separaciones de oficio que se presentaban entre médicos y cirujanos. Un primer grupo de enfermedades accidentales se relacionaba con el devenir de los cuerpos en lugares adversos o en el trabajo; este tipo de terapias se encontraban relacionadas con la cirugía, como un brazo roto o una herida en el pecho, tareas para las que se aplicaban ciertas estrategias de incidencia directa en los cuerpos, como limpiar, coser y encajar. El segundo grupo se refiere a aquellas enfermedades de tipo crónico, como la gota o la ictericia, que requerían tratamientos permanentes y sofisticadas preparaciones de tradición europea con las cuales se atacaban tanto los síntomas como el origen de la enfermedad. Habría que incluir en este grupo aquellas prácticas terapéuticas que buscaban prevenir las enfermedades y que eran costumbres arraigadas dentro de la tradición española, básicamente las sangrías y las purgas. 


\section{FRONTERAS}

de la historia

El principal problema radicaba en la identificación. Si a alguien le sangraba el cráneo a causa de una fractura o presentaba hinchazón o dolor en una parte del cuerpo, médicos o cirujanos sabían qué hacer: coser el cráneo, drenar la parte. Pero ante manifestaciones mentales como delirios, convulsiones e irracionalidades, los médicos debían asegurar el tipo de enfermedad para así utilizar el correspondiente tratamiento.

La división interna de los profesionales en artes médicas no era sólo nominal, sino que se refería a diferentes formas de trabajar sobre los cuerpos. Estas diferencias se presentaban de forma explícita entre los cirujanos y los médicos y pueden ilustrarse teniendo en cuenta dos testimonios sobre la práctica: el primero, una serie de cartas escritas en Santafé por el cirujano no titulado Miguel Cepeda de Santacruz (AGN, $M$ 11, f. 30) y el segundo, las historias clínicas consignadas en los Discursos medicinales, del médico Juan Méndez Nieto.

Los cirujanos fueron fundamentales en el tratamiento de las enfermedades y en la identificación de fenómenos particulares al nuevo mundo que afectaban de manera directa la práctica de las artes medicinales y que enfocaban el valor de la experiencia como un criterio imprescindible para tener curas exitosas. Sirve aquí para ilustrar el valor de la experiencia en la cirugía el caso de Miguel Cepeda de Santacruz, cirujano residente en Santafé que en 1620 fue acusado de no tener títulos a raíz de la muerte de Melchor Rico, un prestante mercader muerto por una mala purga. La defensa de Cepeda es ilustrativa por cuanto enfatizó la experiencia en la profesión sobre la necesidad de títulos. Esta practicidad era característica de los cirujanos, quienes fueron los primeros en identificar la necesidad de una adecuación de las terapias en términos de inclusión de nuevos componentes y revaloración de arraigadas costumbres.

Cepeda consideraba que debía permitirse el ejercicio de la cirugía en el Nuevo Reino sin títulos, pues lo importante era que el practicante hubiera vivido lo suficiente en las Indias para naturalizarse y así poder comprender las características de las enfermedades y las curas en estas latitudes. Sin duda, la forma como se ejerció la medicina en el Nuevo Mundo tenía características que la diferenciaban de la medicina clásica, no solamente por las distintas enfermedades contra las que se enfrentaba, sino también por las particularidades del comportamiento de los cuerpos humanos en estas latitudes.

Para Cepeda, era fundamental demostrar su origen europeo y su conocimiento de las autoridades clásicas. En el nivel de la medicina, resultaba indispensable 
demostrar que se había pasado por el aprendizaje en Europa, ya que ésta era la única manera de legitimar el conocimiento. Pero quizás algo que importante, dado que el cirujano Cepeda vivía en Santafé desde hacía más de 30 años, fue la mención de personajes modernos de la medicina española, pues en la lejanía de Santafé y su aislamiento geográfico estaba enterado también de las revisiones a las teorías clásicas.

Otro elemento que vale la pena resaltar es la importancia que le daba a los conocimientos que habían sido adquiridos por la práctica y la observación de resultados. Para él, ni el mismo médico del rey de España con su corte ultramarina podría venir a Indias y tener éxito inmediato con sus intentos de curar, pues quedarían abrumados por todo lo que no podía aprenderse con libros y maestros. Eran necesarios nuevos conocimientos que hasta ese momento, por la práctica y observación, se estaban construyendo. Así, por ejemplo, sólo a partir de la experiencia en Indias le había sido posible darse cuenta de que el vino, simple comúnmente administrado para cualquier enfermedad en Europa, aquí resultaba contraproducente para un dolor de costado o una fiebre alta.

La práctica de la medicina se encontraba fundamentada en una aplicación más directa de los contenidos de los cánones tradicionales y reconocidos como válidos en las universidades. En este campo del saber se le otorgaba gran importancia a las habilidades diagnósticas del galeno. Para observar las características del diagnóstico es útil la referencia a los Discursos medicinales de Juan Méndez Nieto, donde realizó una intensa labor descriptiva siguiendo el método galénico de la historia clínica. Méndez vivió en Cartagena de Indias y fue allí donde en 1607, a los 80 años de edad, escribió el único texto que le sobrevive. En su obra refiere las enfermedades y terapias de la época e inscribe su narración en un rico escenario cultural; describe el puerto de Cartagena, las posadas de los marinos y la competencia en un mercado rentable donde el mar traía consigo enfermedades y curas.

El autor menciona que en sus valoraciones diagnósticas solía descubrir al enfermo y palparlo. Una vez identificados los síntomas generales, el lugar hinchado o doliente, se procedía de forma rigurosa. Se le recetaba una dieta por algunos días y una sangría para drenar los humores mal acumulados. Para complementar la lectura de signos se analizaba el espesor y coloración de la orina. Estos saberes provenían de la tradición del renacimiento español, cuyos 


\section{FRONTERAS}

de la historia

pilares eran Hipócrates y Galeno ${ }^{13}$. Una vez determinada la dieta y realizada la sangría, el médico podía recetar algún fármaco para ayudar al reestablecimiento del enfermo. Algunas sustancias eran importadas desde España, pero, como Méndez Nieto anota en sus discursos, las plantas secas que provenían de Europa no contenían las cualidades en las mismas proporciones y comúnmente había de usarse mayor cantidad que la que aparecía ordenada en las fórmulas.

\section{Conclusiones}

En el contexto urbano del siglo XVII del Nuevo Reino de Granada, tanto las boticas como los boticarios eran objeto de control por parte del Estado y de la comunidad médica, compuesta por diversos especialistas, entre los que se han resaltado los médicos, los cirujanos y los boticarios. Estos controles se realizaban por medio de las visitas (AGN, $M A$ 6, ff. 880-1033). A partir de este tipo de documentos ha sido posible reconstruir las dinámicas de control sobre boticas y boticarios identificando algunos problemas comunes durante la primera mitad del XVII.

La botica como local comercial donde se vendían sustancias medicinales era examinada para vigilar la correcta distribución de los espacios, el estado y la calidad de las medicinas almacenadas y la precisión de las sustancias preparadas. A lo largo de los pleitos se muestran las dinámicas de abastecimiento de las boticas, la compra de productos simples o compuestos en los galeones, la reventa, el préstamo y el intercambio entre miembros del sistema médico y la asociación de boticarios en empresas comerciales para enviar por medicinas (AGN, MA 6, ff. 880-1033).

Se han encontrado pleitos que conciernen a la jurisdicción legal para el control de las boticas y su revisión y control. En ellos los boticarios consideraban que debía ser un boticario titulado el visitador de las boticas, no un cirujano o un médico, por no ser expertos en el arte. El mercado de sustancias era competido no sólo entre boticarios rivales, sino también con otros miembros del sistema, ya que los límites entre las disciplinas, aun cuando estaban regulados, no se hacían siempre efectivos y tanto cirujanos como médicos podían en la práctica

\footnotetext{
${ }^{13}$ Solano Alonso ha realizado la tarea de identificar y distribuir las citas que hace Méndez Nieto en su texto y ha encontrado que el principal es galeno, seguido por Hipócrates. En términos de la historia natural y la farmacia, Méndez cita a Plinio el Viejo, a Dioscórides y al árabe Mesue. También cita a algunos autores más o menos contemporáneos de la escuela de Salerno, de Salamanca, italianos y españoles tratadistas, en cuyas obras se revisaban y se revaluaban los conocimientos de los autores clásicos.
} 
fabricar medicinas (Méndez). Así mismo, se debe considerar la presencia de otros sistemas relacionados con prácticas culturales y nociones sobre el tratamiento de la enfermedad distintos de la tradición europea que compartían el escenario de las terapias en el periodo estudiado (Gutiérrez y Vila).

Durante las visitas se revisaban los títulos de los boticarios que les otorgaban la legitimidad para desempeñarse en el oficio. Estos títulos se adquirían mediante la presentación de un examen ante autoridades competentes que avalaban al aspirante y le daban el permiso para fundar botica y fabricar medicamentos. En los exámenes se evaluaban dos niveles: el teórico y el práctico (AGN, M 11). En cuanto al teórico, vale resaltar la importancia de los libros y manuales de farmacia, así como el sustento epistemológico del oficio. Los manuales explicaban los mecanismos para la identificación de simples, la extracción de cualidades y los mecanismos de mezcla y transformación de las sustancias a partir del uso de artefactos especializados. Los exámenes practicados en el nuevo mundo no atestiguan una diferencia importante en el reconocimiento de las dificultades propias del reconocimiento, uso y transformación de las sustancias en las condiciones especificas de la práctica en el Nuevo Mundo; sin embargo, los testimonios de los practicantes evidencian la importancia que se les atribuía a la experiencia y a la experimentación con sustancias para sustituir las que no se tenían y encontrar reemplazos más fáciles de obtener.

Por último, se encuentra documentación que muestra cómo se establecían los vínculos entre el diagnóstico y el tratamiento, lo cual nos habla, a su vez, de las relaciones entre médicos, crújanos y boticarios (AGN, C 17; MA 1, ff. 90-137; $M$ 11). Los primeros visitaban al enfermo, lo diagnosticaban y escribían una receta con el tipo de medicamento y la dosis; esta receta era enviada al boticario para su preparación. Sin embargo, de acuerdo con los difusos límites entre las especializaciones, el enfermo podía acudir directamente al boticario, quien en ocasiones recetaba por su cuenta.

A partir de las recetas se presentan dos formas de tratamiento para dos tipos distintos de enfermedad: la accidental y la crónica. Éstas se relacionan con las funciones de las sustancias administradas; se establecía una diferencia entre las recetadas por cirujanos, de carácter más directo, inmediato y de choque, y las de los médicos, más inclinados al tratamiento de males internos, de larga duración y complejidad. 
FRONTERAS

de la historia

Vol. 12 / 2007

\section{Bibliografía}

\section{Fuentes primarias}

Archivo General de la Nación, Bogotá, Colombia (AGN).

Asuntos civiles Cundinamarca (ACC) 20.

Criminales (C) 17.

Médicos y abogados (MA) 1 y 6.

Miscelánea $(M) 11$.

$\operatorname{Notaria}(N) 1$.

Testamentarias de Cundinamarca (TC) 20.

Archivo Histórico de Pamplona, Pamplona, Colombia (AHP).

Archivo notarial (AN) 16, 20, 27.

Archivo Regional de Boyacá, Tunja, Colombia (ARB).

Actas de Cabildo (AC) 1893.

Dioscorides, Pedanius de Arnazabeo. Pedanii dioscoridis anazarbei, de medicinale materia libri sex, [...].1 ${ }^{\mathrm{a}}$ ed. Excudebat Viennae: Baltazar Arnoullet, [¿1543?].

López de León, Pedro. Practica y teorica de las apostemas en general y particular: Question y practicas de cirugia, de heridas y otras cosas nuevas y particulares. Aora nuevamente se han añadido los instrumentos ferrales. Parte 1 y 2. Calatayud: Josef Vicente Mola, 1689.

Martínez de Leache, Miguel. Discurso pharmaceutico sobre los canones de Mesue. Pamplona: Martín de Labayen y Diego de Zabala, 1652.

\section{Fuentes secundarias}

Aguilera, Antonio de. Exposición sobre las preparaciones de Mesue. Biblioteca Universidad Complutense de Madrid. 10 sep. 2007, $<\mathrm{http}$ ://cisne.sim.ucm.es/search*spi/?searchtype=t\&searcharg=Exposici 
$\% \mathrm{C} 3 \% \mathrm{~B} 3 \mathrm{n}+$ sobre + las + preparaciones $+\mathrm{de}+$ Mesue $+\&$ searchscope $=6 \& \mathrm{~S}$ ORT $=$ D\&extended $=0 \&$ SUBMIT $=$ Buscar $\&$ searchlimits $=\&$ searchorigar $\mathrm{g}=\mathrm{aMonardes}+\mathrm{Nicol} \%$ 7B226\%7Das $+>$.

Castiglioni, Arturo. Historia de la medicina. Barcelona: Salvat, 1941.

Font Quer, Pío. Plantas medicinales. El Dioscórides renovado. Barcelona: Península, 1999.

Gutiérrez de Pineda, Virginia y Patricia Vila de Pineda. Medicina tradicional de Colombia. 2 t. Bogotá: Universidad Nacional de Colombia, 1985.

Herrera, María Teresa y María Estela Gonzá de Fauve, dirs. Textos y concordancias electrónicas del Corpus Médico Español. Estados Unidos: Universidad de Madison, 1997.

Laguna, Andrés de. Annotationes in Dioscoridem Anarzabeum. Biblioteca Universidad Complutense de Madrid. 10 sep. 2007, $<$ http://alfama.sim.ucm.es/dioscorides/consulta_libro.asp?ref=X533705 788\&idioma $=0>$.

Laín Entralgo, Pedro. Historia de la medicina. Barcelona: Mason, 1978.

Lanning, John Tate. El Real Protomedicato. La reglamentación de la profesión médica en el imperio español. México: Instituto de Investigaciones Jurídicas; Universidad Autónoma de México, 1997.

Martínez de Leache, Miguel. Tratado de las condiciones que ha de tener el boticario para ser docto en su arte. Biblioteca Universidad Complutense de Madrid. 10 de septiembre de 2007 $<\mathrm{http}$ ://cisne.sim.ucm.es/search*spi/?searchtype=t\&searcharg=Tratado+ $\mathrm{de}+$ las + condiciones + que + ha + de + tener + el + boticario + para + ser + docto $+e$ $\mathrm{n}+\mathrm{s} \&$ searchscope $=6 \&$ SORT $=$ D\&extended $=0 \&$ SUBMIT $=$ Buscar \&searc hlimits $=\&$ searchorigarg $=$ tExposici $\% 7 B 226 \% 7 D o n+$ sobre+las + preparac iones + de + Mesue $+>$.

Méndez Nieto, Juan. Discursos medicinales. 1607. Salamanca: Universidad de Salamanca; Junta Castilla y León, 1989.

Monardes, Nicolás. Primera y segunda y tercera partes de la Historia medicinal, de las cosas que se traen de nuestras Indias Occidentales, que siruen en Medicina; Tratado de la Piedra Bezaar y de la yerua 


\section{FRONTERAS}

de la historia

escuerçonera; Dialogo de las grandezas del hierro y de sus virtudes medicinales; Tratado de la nieue y del beuer frio. Biblioteca Universidad Complutense de Madrid. 10 sep. 2007 $<$ http://cisne.sim.ucm.es/search*spi/aMonardes+Nicol $\{226\}$ as+/amonar des + nicolas $/ 1 \% 2 \mathrm{C} 2 \% 2 \mathrm{C} 26 \% 2 \mathrm{CB} /$ frameset $\& \mathrm{FF}=$ amonardes + nicolas $\& 1$ $6 \% 2 \mathrm{C} \% 2 \mathrm{C} 23>$.

Pastor Frechoso, Félix Francisco. Boticas, boticarios y materia médica en Valladolid (siglos XVI y XVII). Valladolid: Junta de Castilla y León; Consejería de Cultura y Turismo, 1993.

Plinio el Viejo. Historia natural. Libros I-XI. Madrid: Gredos, 1995.

Recopilación de leyes de los reynos de las Indias. Mandadas imprimir, y pvblicar por la Magestad Católica del Rey don Carlos II nuestro señor. 4 t. Madrid: Cultura Hispánica, 1973.

Rodríguez de Tudela, Alonso, trad. Compendio de boticarios. 1515. Estados Unidos: Universidad de Madison, 1997.

Rodríguez, Martha Eugenia. "Legislación sanitaria y boticas novohispanas". Estudios de Historia Novohispana 17 (1997). 10 sep. 2007 $<$ http://www.ejournal.unam.mx/historia_novo/ehn17/EHN01708.pdf $>$.

Ronderos, Paula. "Evidencias históricas de las prácticas médicas y farmacéuticas en la Santafé del siglo XVII. El caso de la muerte por purga". Documentos CESO 66 (2004).

Siraisi, Nancy. Medieval and Early Renaissance Medicine. An Introdution to Knowledge and Practice. Estados Unidos: The University of Chicago Press, 1990.

Solano Alonso, Jairo. Salud, cultura y sociedad: Cartagena de Indias siglos XVI y XVII. Barranquilla, Colombia: Universidad del Atlántico, 1998.

Fecha de recepción: $1^{\circ}$ de marzo de 2007.

Fecha de aprobación: 30 de julio de 2007. 